\title{
Accreditation of Distance Learning
}

\author{
Ergün Demirel \\ Faculty of Maritime, Piri Reis University, Turkey
}

Copyright $(2016$ by authors, all rights reserved. Authors agree that this article remains permanently open access under the terms of the Creative Commons Attribution License 4.0 International License

\begin{abstract}
The higher education institutes aspire to gain reputation of quality having accreditation from internationally recognized awarding bodies. The accreditation leads and provides quality assurance for education. Although distance learning becomes a significant part of the education system in the $21^{\text {st }}$ century, there is still a common opinion that the quality of distance education is lower when comparing with the classical conventional classroom education. The accreditation will serve public accountability and play a critical role to change this opinion. The aim of this study is to evaluate how accreditation standards can be applied for the distance learning programmes and which areas are benefited by accreditation standards. The study is based on an investigation to identify applicable accreditation system for distance learning including definition of problem areas and continues with production of proposal to facilitate application of accreditation for such systems. The results of this study may lead education providers to establish an accredited distance learning system and ensure the people on quality of their work.
\end{abstract}

Keywords Total Quality Management, Quality Assurance, Distance Learning, Quality in Education, Accreditation, CAF (Common Assessment Framework)

\section{Introduction}

A recent development in the soft skills training space is the growing number of partnerships between e-learning vendors and academic institutions to create "virtual universities" online. These universities are intended to offer higher education courses, corporate training, and certification programs. This business model combines two groups of market participants with mutual interests (Bachman, 2000). The distance learning business is a challenging market all market sharers are trying to achieve better quality and advantages for their customers using all available marketing methods. The quality and reputation are the most important players in the market and players are very keen to achieve best quality in their field.
The accreditation is the essential element of Quality Assurance system of any education and training institute. It has been applied early 1960s in the United States and some western countries and it is now expanded into many other countries across the world. Nowadays accreditation has a significant value for reputation of any education institute. Hence today the most important issue for the reliability and quality of an educational establishment is the accreditation.

The quality assurance is the process that ensures all respective institutions are applied approved qualifications and assessed to the same high standard. The accreditation system assures that the institute has required systems (programmes, infrastructure, lecturers, assessment procedures etc.) to deliver assigned programmes and assessments of the students are made applying approved standards. The accreditation process helps to ensure managers, lecturers, internal verifiers and assessors are supported in assessing to a consistent and high standard.

The serious concerns about the quality and adequacy of distance education are suggested. Especially people who are trained in the classical education system have some concerns about the quality of distance education. This concern goes to the issue of accreditation In order to determine the real value and importance of the distance education in the educational system, the application of this system must be considered carefully.

The reputation gained by the way of accreditation of an education institute is highly important. It will directly affects motivation and commitment of the both administrative and teaching staff. This will increase the quality of the work achieved and achievement of long term objectives of the institute in a very short span of time. The enhanced reputation attracted better faculty which in turn led to improved pedagogy. The reputation also led to higher quality of applicants and better outcomes. Faculty benefits of professional development led to improved efficiency, commitment, accountability and satisfaction.

The international quality standards for distance learning have already been defined by ISO 29990. The accreditation has a significant importance to prove the quality of any type of education and training. ISO 29990:2010 provides a unified standard for learning service providers, including corporations, vocational institutions, and life-long learning 
centers, around the globe. The certification of distance learning courses is required to ensure that the design, development and delivery of the learning experience meet the standards established by ISO requirements.

\section{Research Method}

The aim of this study is to evaluate how accreditation standards can be applied for the distance learning programmes and which areas are benefited by accreditation standards. The study is based on an investigation to identify applicable accreditation system for distance learning including definition of problem areas and continues with production of proposal to facilitate application of accreditation for such systems.

The study will be conducted in three phases. Firstly, the distance learning and accreditation concept and, existing accreditation applications methods will be will be envisaged. Based on the existing accreditation methods, new procedures for accreditation of distance learning methods will be discussed and, suitability and reliability of these proposed methods will be tested in the second phase. Finally, as a result of the discussions the most suitable accreditation method (s) will be proposed.

The results of this study may lead education providers to establish an accredited distance learning system and ensure the people on quality of their work.

\section{Quality Assurance in Education}

\subsection{Quality Assurance System}

\subsubsection{Quality Concept}

The quality has been expressed in many documents in different wordings. The following is a resume of the quality concept excerpted many related documents and introduced in the International Quality in the Higher Education Conference 2016 conducted in Turkey. [1]

Quality is the totality of features and characteristics of a product or service that bears on its ability to satisfy stated or implied needs.

Quality Assurance is all those planned and systematic actions necessary to provide adequate confidence that a product or service will satisfy given requirements for quality.

Quality Control is the operational techniques and activities that are used to fulfil requirements for quality. The Quality Control also includes the systematic process of measuring actual quality performance and comparing it with a given standard to enable action on the difference.

The research studies are also concerned with quality management.

Quality Management is the aspect of the overall management function that determines and implements the quality policy.
Total Quality Management is defined as the management philosophy and the organizational practices that aim to harness the human and material resources of an organization in the most effective way to achieve the objectives of the organization.

\subsubsection{The Basis of Quality Assurance System for Education}

The main aim of the quality assurance systems is to approve an education institute and programme/courses delivered by this institution. The accreditation authority is the key element of this system. This authority is responsible to identify capacity of the institution and provide support to enable it to be capable to deliver definite education programmes in accordance with predesigned standards. It would be better to understand both the content of the accreditation and the role of an accreditation organization giving an example. The Pearson is an internationally recognized accreditation institute and following paragraphs explains its applied Quality Assurance model [2].

- At center recognition and qualification approval when Pearson carries out checks to assure that sufficient, appropriate and high quality human and physical resources are in place to ensure that everything is in place to start delivery of the customized qualification

- Internal verification which is a quality process internal to each organization

- Standard verification which is conducted by Standards Verifiers who are appointed by Pearson. It is a system designed to ensure that the assessment methods that are used by the center are fit for the purpose and that assessment decision made by respective center's assessors are valid, reliable and consistent with benchmarks

The accreditation is carried out at an appropriate time which allows completion of all required action to be done by both accreditation and accredited institutes. It starts at the beginning of the academic year and completed after two or three months following the end of the final assessments to allow verifiers check the assessments.

\subsection{Details of Quality Assurance System Required for Accreditation}

The followings are the basis for QA criteria for accreditation for an education and training institute;

- Physical resources for the programme should be suitable to support the programme which will be delivered

- Number of the teaching staff should be sufficient and they should be qualified and experienced including a staff development plan

- A reasonable delivery programme

- A system should be established to evaluate students' and staff views.

- The responsibilities of all staff deployed for delivery, 
assessment and quality assurance

- Sufficient technical and administrative support staff should be available

- A detailed document for each programme should be available covering following issues[2];

- Description of the programme

- Rationale for the programme

- Aims

- Intended learning outcomes

- $\quad$ Programme structure

- $\quad$ Learning and teaching strategies

- Assessment strategy

- $\quad$ Student experience - support, progression and achievement.

- $\quad$ Programme review and evaluation
- Entry regulations

- Academic regulations

- Examinations - regulations and procedures.

- Institution Management Structure

- Appeals - procedures.

- Counselling and advice

- Summary Syllabuses

Internal Verification audit process flow chart of an education institute is shown in Figure 1. This figure clearly explains relations between assessors and internal verifiers to ensure all assessments are conducted in accordance with the established course aim and objectives. It is a time consuming process that requires many paperwork to be done and close cooperation between respective staff.

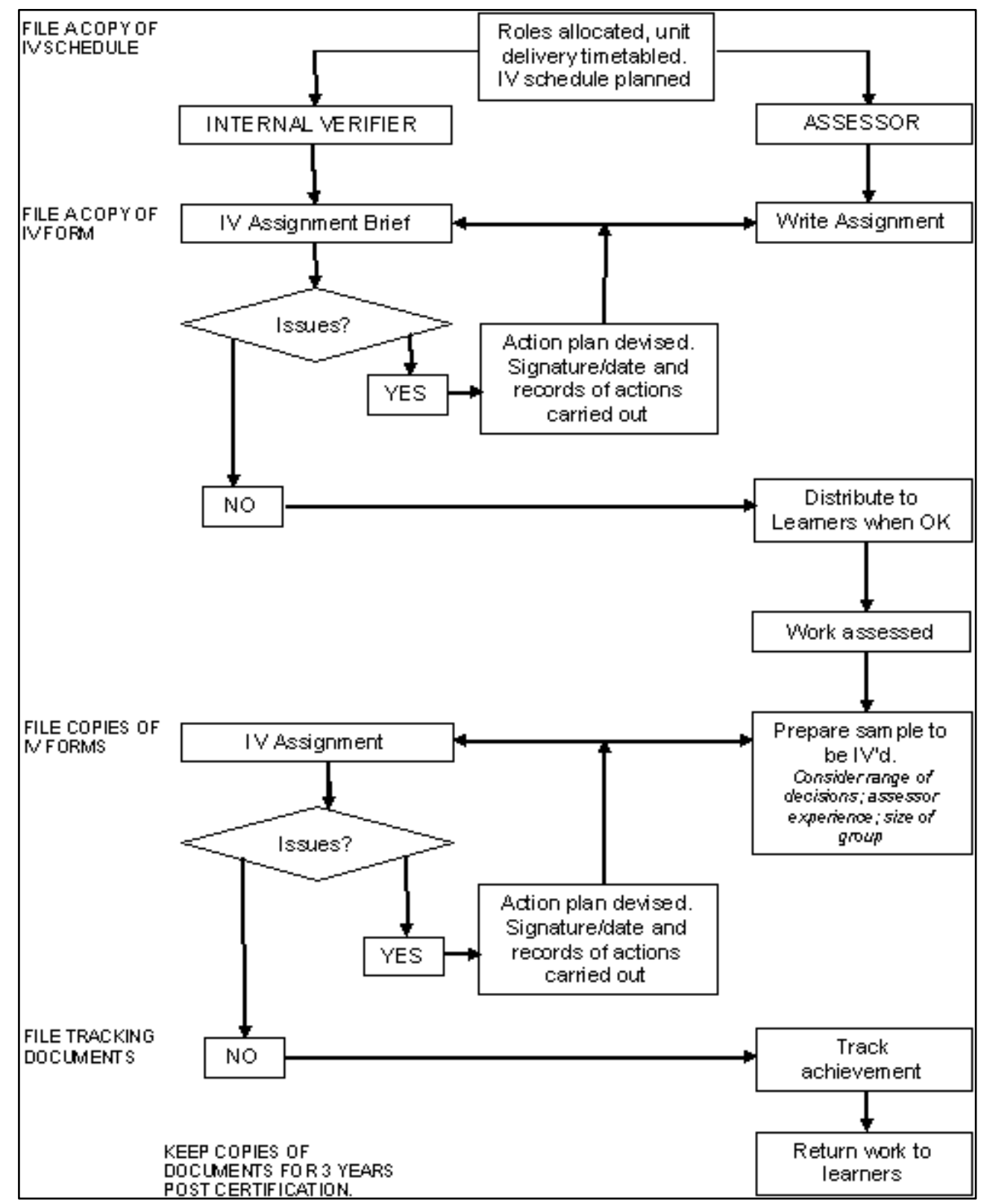

Figure 1. Audit System Flow Chart 


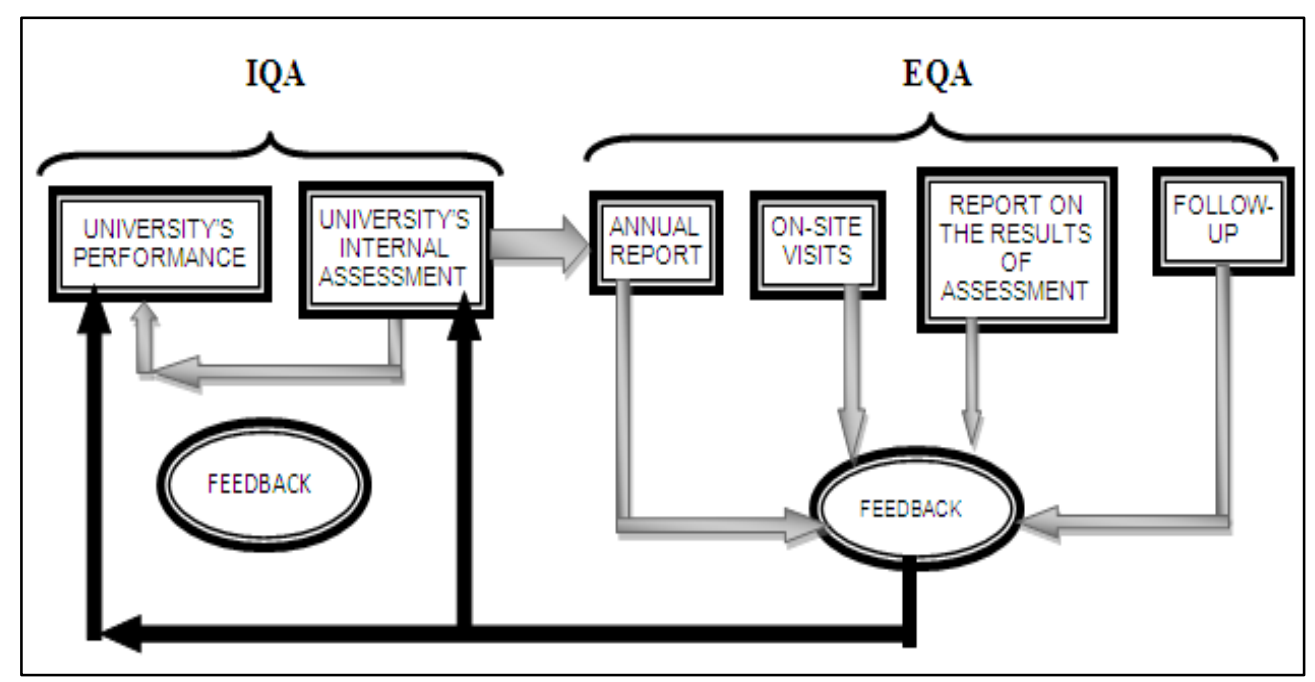

Figure 2. The 'Continuum' between IQA and EQA.

The 'Continuum' between Internal and External Quality Assurance System (IQA and EQA) is shown in Figure 2. The IQA process is conducted by institute staff. The External Verification process is conducted by Accreditation institute staff in collaboration with institute staff.

\section{Discussion}

\subsection{Importance of Accreditation in Education}

Just a few years ago, almost no one saw accreditation as a major force change in higher education. It was generally regarded as something of an anachronism, a ritual institutions had to go through periodically just to say legit. Bit accreditation is back. Anyone doesn't think so should try "Googling "accreditation: even with qualifying phrases like "student learning" or "accountability", the curious reader would have plow through 200,000 web sites [3].

The higher education institutes aspire to gain reputation of quality having accreditation from internationally recognized awarding bodies. The accreditation leads and provides quality assurance for any type of education. The distance learning become a significant element of the education system in the $21^{\text {st }}$ century, but there is still a common opinion that the quality of distance education is lower when comparing with the classical conventional classroom education. The accreditation will serve create accountability and play a critical role to change this opinion.

Academic institutions, the major producers of branded educational content, recognize the need to offer and distribute their degree programs online, but generally do not have the technical or financial capacity. E-learning companies, on the other hand, see the opportunity of building a brand more quickly and less expensively using the "Intel inside" concept. As more competitors enter the market, we believe that accreditation of the new online universities and exclusivity of partnerships will be essential differentiators among e-learning competitors [4].

\subsection{Obtaining better quality with Accreditation}

The aim of the accreditation in the education is to provide Quality Assurance. To ensure a better quality accreditation some major measures should be taken. Wergin [4] states that "accreditors must also maintain strong ties with their member institutions. A system based on peer review requires that these institutions be willing to go along with needed changes, which in turn depends upon accreditors not" playing gotcha," as Ralph Wolff off the Western Association has put it. In short, accrediting commissions face the difficult task of both assuring quality and improving quality".

Nowadays many educational institutes firstly provide accreditation from related national and international institutions of which are in conjunction with their programmes. As a good example, ImarEST (Institute of Marine Engineering, Science and Technology) accredits all universities handling Marine Engineering Programmes and RINA (Royal Institute of Naval Architects) accredits Naval Engineering programmes in the United Kingdom.

Another important issue is that accreditors should be internationally recognized reputable institutions to eliminate any queries on the quality of accreditation. With accreditation from reputable institutions, students, employers, and the society can be confident that the program meets the quality standards and produce graduates prepared to enter a global workforce. Pearson Edexcel, ABET are the examples for famous accreditation institutions operating worldwide.

All countries establish their own accreditation system. In order to be recognized in the different countries, accreditation institutions require to be recognized by respective countries' respective accreditation authorities. Otherwise the diplomas provided from foreign education institutes will not be accepted in the other countries if this process has not been actuated/ activated. Lloyd (2007) draws 
attention on this issue "To avoid any pitfall, the organization should make a business plan and this business plan should address possible legal complications. The organization should carefully investigate legal complications, before they decide to accept a plan for the adaptation of the accreditation system from other countries.

\subsection{Simplification of the System Application}

One of the models which is suitable for public institutions, including educational and training institutions, is the European Quality Management tool for the Public Sector called the "Common Assessment Framework (CAF)" [5]. The CAF was primarily designed as a self-evaluation tool for public sector organizations at both local and national levels. The model is also intended to facilitate the introduction of more detailed evaluation criteria into the public sector evaluation process [6]. Its content and structure follow the same logic well-known as Quality Awards models (Quality Evaluation Model of Educational Projects 2012) [7]. The model involves five evaluation areas describing operations ('enablers'): leadership, strategy and planning, human resources management, partnerships and resources, process and change management [8].

Suban and Suban have proposed that the key aspects of the evaluation method of the CAF could improve the application of the quality system: Simplification of assessment, Unification of assessment, Recognition of Good Practices, and Reduction of the influence of the human factor.

Unfortunately accreditation process requires access paperwork which bores all concerned parties. Before creating an accreditation system for distance learning a study should be made on the simplification of assessment procedures. Taking into account the good practices in the other countries, a new unified assessment procedure to be applicable in the different countries should be introduced. Creation of fit to purpose IT programs for planning the QA activities, preparation and evaluation of the assessment papers will reduce the paperwork and the work spent as well as increasing check and control process [2].

\subsection{Additional works}

The internal verification is the hardest part of the accreditation. The sufficient number qualified internal verifiers should be included in the distance learning programmes. There should be a leading internal verifier to control the overall system. The other verifiers may be deployed between the lecturers deployed in the programme. A continuous training programme for all internal verifiers and assessors is highly important for the success of the system.

Another issue is the arrangement of the meeting of the external verifiers with learners which is important to ensure the system. As a nature of the distance learning programme it is unlikely possible to arrange such a meeting for all learners. The arrangement of the meeting with the learners may be achieved for only selected students who are living in the reachable distances.

\subsection{Facilitation of Accreditation for Distance Learning}

Centers must notify Pearson of their intention to use Distance Learning and/or Distance Assessment for any qualification, or part of a qualification, at the point of qualification approval. Where a center is already approved to deliver a qualification face-to-face, and wishes to deliver to some learners wholly or mainly through distance means, the center must submit a further approval application. To ensure compliance with the general approval requirements for a specific qualification, centers must demonstrate that they can meet the standards set out in the DLSA (Distance Learning Quality Self-Assessment) [9]. This is an important issue which facilitates the accreditation process for the education institute which already delivers face-to-face programmes.

The improved ICT technologies provided as many opportunities to create reliable and effective test and assessment techniques which are essential to support a programme delivered by distance education. Ridgeway [10] states that 'Open-web' examinations offer a parallel to open-book examinations. One virtue of such examinations is that they are more 'authentic' than conventional examinations, in that, outside educational contexts, one rarely has to answer a substantive question without any resources."

\subsection{Preparations}

Bower [11] states that "A National Center for Education Statistics (NCES) 1997 report indicated that about 60 percent of higher education institutions provide training opportunities for distance learning faculty. This means that 40 percent of the institutions offering distance learning courses asked faculty to teach these courses without providing any special preparation for the experience. Of the 60 percent providing special training, about one quarter required faculty to have training in distance learning technology, 13 percent required training in curriculum development and 17 percent in teaching methods for distance learning. The NCES survey did not address the depth or extent of the training that was provided, an important consideration in the issue of instructor preparedness [12]. The lecturers and tutors should be trained on the distance learning techniques before starting the delivery of distance learning. To achieve that at least a quarter/semester training should be planned including preparation of course material, tests and assignments and effective delivery methods

\subsection{Proposed System}

The accreditation system consists of two main elements; approval of the suitability of center to deliver a programme and approval of the success of delivery of education. As part of the process for approving the suitability of center to 
deliver a programme, accreditation institute will require access to materials, course plans, and assessment plans and learners support systems. The center should prove that they are ready to deliver designated programmes as distance learning. This should be achieved at the beginning of the accreditation process and should be checked/controlled during the continuing verification periods.

Accreditation institute should monitor the appropriateness delivery of the programme using their own standard verification process. For approval of the success of delivery of education a structured verification system for Distance Learning should established and operated by both education and accreditation institutes.

The education institutions which already have an accreditation system may easily apply the accreditation for the Distance Learning programmes. This is an important advantage to encourage the education institutes which looks for accreditation for their distance learning programmes.

In order to achieve a practical accreditation system the following model is proposed (Figure 3);

- Accreditation of the Education Institute (as initial process) to ensure availability and suitability of teaching material and lecturers/tutors and of internal verifiers to support the teaching activities

- Approval of the success of the students work for certification of the institute by the way of external verification conducting by accreditation institute.

Firstly the institute should be prepared for validation of the center to prove that it is suitable to deliver the programmes. This process covers the preparation of course material, programme delivery details, lecturers/tutors suitability to deliver such a programme. The verifiers also check the capacity of the administration and lecturers to apply internal verification which requires a special training on the internal and external verification process. The institute $s$ should prepare a detailed document for each programme covering the issues defined in the subparagraph 3.2. This document should be prepared one for administrative and teaching staff and one for students to meet the requirements of all concerned parties. Every accreditation institution has his own procedures to be followed for the initial verification process. The center should make their preparation in accordance with this procedure to facilitate initial verification.

The second phase is a dynamic process which should be conducted permanently. Normally external verifier(s) visits the center at the end of each semester and check the assessment activities in this period. This requires control of the student works (examinations, practical study, assignments etc.) to evaluate that the assessments has been conducted to meet criteria based on the learning outcome of each courses delivered. If the verifiers found any discrepancy in the system they inform the center to take corrective actions. If major problem areas are found the accreditation of the center may be permanently or temporarily suspended. The verifiers also controls if the center sustains the sources required to deliver the programme. If they found some additional sources required to handle the programme, the center should be informed and be given a definite period to compensate the missing issues. Normally the verifiers must meet the student registered to the programme to realize "learner's satisfaction" and some other discrepancies which has not been investigated in the inspection period. The learners taking the programme are not found in the center due to nature of the distance learning programmes. In order to achieve this verifier-learner meetings both center and accreditation institute should create a practical method such as meeting with the learners in the close distance, online video conferences, detailed questionnaires for students to define problem areas. 


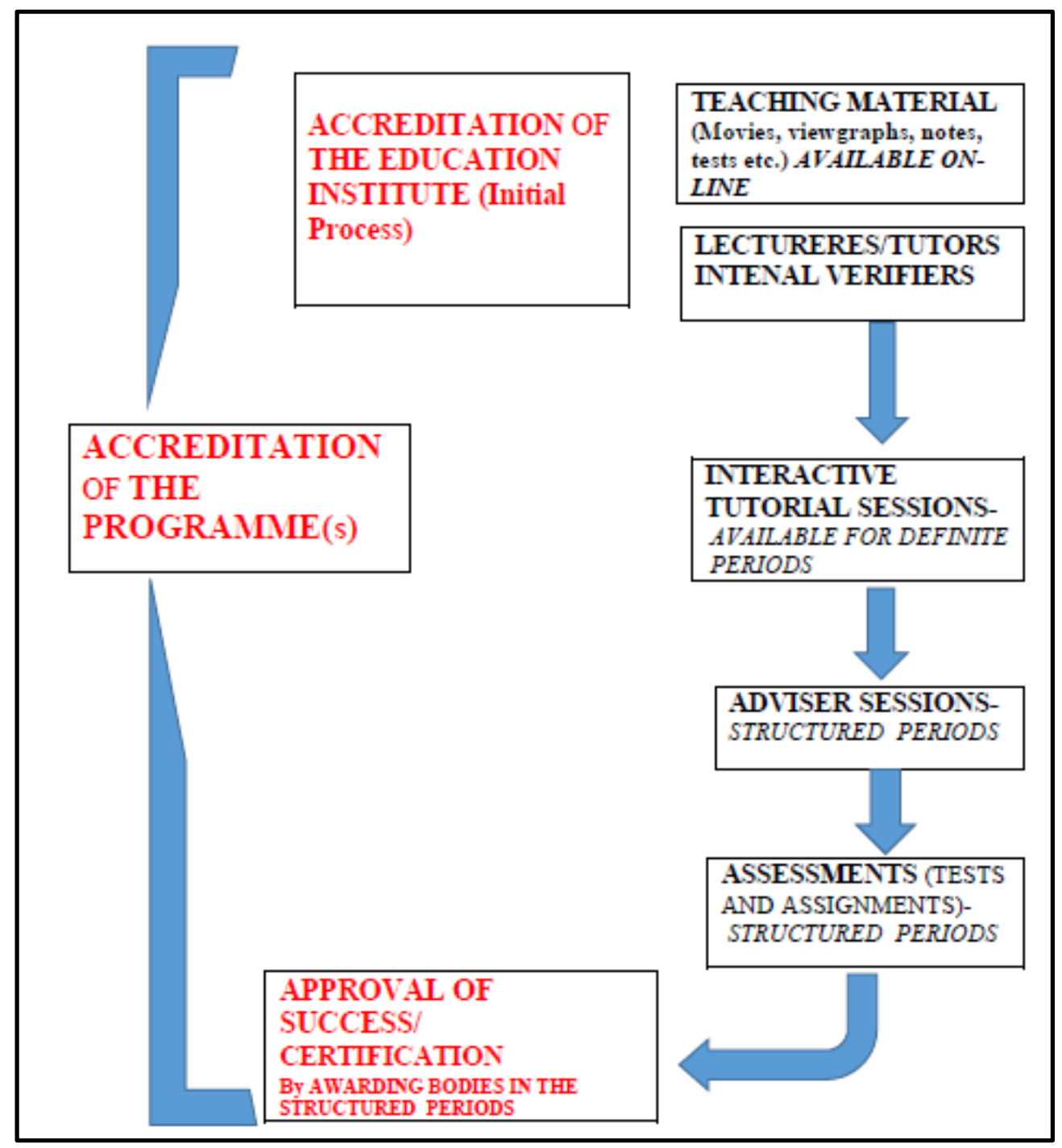

Figure-3. Proposed Practical Accreditation Model

\section{Conclusions}

The application of accreditation for distance learning is an essential issue for both reputation of the institute and ensures the quality of the programme delivered. Most of the universities have already had accreditation and also delivers distance learning programmes. It will be very easy for these universities to have accreditation for distance learning courses just making some minor amendments to existing system to meet special needs for distance learning.

As a result of the study the following issues are defined as the most important areas which require to establish an accreditation system for distance learning;

- In order to change the common opinion about the quality of distance education, the accreditation of distance learning is necessary. It is not a high cost process but need special actions to meet the requirements of accreditation process.

- The accreditation should be done by an internationally recognized accreditation institute to ensure the people about the quality of the distance learning. This will ensure both reputation of the institute and increase the number of the international students.

- Taking into account the special conditions of distance learning special accreditation procedures should be created without changing the main basis of the quality assurance system.

- Using improved ICT system a particular test and assignment module distance learning for should be created and this system should be compatible to apply accreditation process. This will decrease the paperwork and save the time spent for internal and external verification.

- The ISO 29990:2010 (Learning services for non-formal education and training) [13] methods should be fully applied. Some amendments may be proposed for this ISO norm to adopt distance learning procedures.

The following topics are recommended to the organizations which will involve with accreditation: 
- The accreditation and education institutions should establish links with the national accreditation authorities to ensure recognition of the diplomas/certificates by all parties. Otherwise both educations and learners may encounter some legal and administrative problems which may cause some administrative and legal problems.

- A structured training on the accreditation procedures for all managers, lecturers and tutors. This training programme should cover the application of the distance learning and accreditation procedures and processes. And all new teaching staff should get this training before starting to delivery as well as a revision programme for lecturers at the beginning of each academic year.

- The education institutions which already have an accreditation system may easily apply the accreditation for the Distance Learning programmes which already delivered face to face. To achieve that the programme leaders should carefully investigate other requirements for distance learning and make modification as required basis.

The accreditation institutions should make a study to facilitate the application of the system for distance learning programmes in different countries taking into account the following considerations;

- A worldwide assessment procedure for accreditation of the distance learning programmes based on the good practices should be improved.

- The hardest part of the accreditation is the verification process. To overcome difficulties and reduce workload of assessors, the assessment procedures applied in the distance learning should be simplified. Such a simplified system will also facilitate verification process.

- An improved IT programme which is also compatible with the distance learning delivery system will reduce the paperwork and establish a good control and coordination system between education and accreditation institute.

Finally, the distance learning is one of the essential elements of education and training system. The importance of the distance learning will enhance in the near future to meet the rapidly changing learning requirements of the community. There is a big challenge in the education and training sector to enhance their customers. As being in the other business sectors, education sector also needs to reduce the cost and ensure the quality to survive in today's challenging world. The accreditation is the basic factor to ensure the quality in the education. The education providers should carefully investigate accreditation requirements for face to face and distance learning, and actualize the accreditation system for their programmes soon to survive in this highly competitive sector.

\section{REFERENCES}

[1] E. Demirel. A study in the Application of Edexcel Quality Assurance System in Turkey, Procedia -Social and Behavioral Science, 2014 Doi: 10.1016/j.sbspro.2014.09.306

[2] Pearson Self-Regulated Framework Quality Assurance Handbook 2013-2014- Issue 1 - August 2013, Pearson, 2013

[3] J.F. Wergin. Resource Review: Higher Education: Waking up to the Importance of Accreditation, Change Vol. 37, No. 3 (May - Jun., 2005), pp. 35-41, 005, 2005, Online available: http://www.jstor.org/stable/40178168

[4] K. Bachman K. Corporate E-Learning: Exploring A New Frontier, Wrhambrecht $+\mathrm{Co}, 415.551 .8600,2000$, Online available: http://www.internettime.com/Learning/articles/ha mbrecht.pdf.pdf

[5] The Common Assessment Framework (CAF)- Improving Public Organizations through Self-Assessment, EIPA (European Institution of Public Administration), Maastricht, Netherland, 2013

[6] V. Suban and T.D. Suban. MET Quality Measurement - CAF Approach, IMLA 20 Proceedings - July 2012, Terschelling, Netherland, 2012

[7] Quality Evaluation Model of Educational Projects, 2012, Online available: http://www.ctt.uni.lodz.pl/

[8] P. Kovač. Quality Management in Slovene Public Administration: From ISO to CAF and Forward, 3rd International Conference of the Central and Eastern European Countries, Bratislava, 2003

[9] Pearson Distance Learning and Assessment Policy Version 1.6, Pearson Qualification Services, April 2016

[10] J. Ridgway and S. McCusker, D. Pead, Literature Review of E-assessment, Report 10: Futurelab Series, Durham Research Online, Durham University, Bristol, 2007, Online available: http://dro.dur.ac.uk/1929/1/Ridgway_Literature.pdf

[11] L. B. Bower, Distance Education: Facing the Faculty Challenge. Online Journal of Distance Learning Administration, 4(2), 2001, Online Available at: http://www.westga.edu/ distance/ojdla/summer42/bower42. html Council for Higher Education

[12] National Center for Education, Distance education in higher education institutions. 1998, Online available from the World Wide Web at http://nces.ed.gov/pubs98/distance/98062-1.ht $\mathrm{ml}$.

[13] ISO 29990:2010, Learning services for non-formal education and training -- Basic requirements for service providers, Online Available: https://www.iso.org/obp/ui/\#iso:std:iso:29 990:ed-1:v1:en 